\title{
Finding the Appropriate Model to Evaluate the Price Indices of Domestic Agricultural Production in EU24
}

\author{
Joel Chiadikobi Nwaubani, Adanma Ngozi Ohia, Christiana Uzoma Ezechukwu, Peace Opara, \\ Chinwe Adaugo Uzokwe, Uchechi Mgbafor Ezeji
}

\begin{abstract}
The structure of the European Union producer price indices, nominal total agricultural production varies from one country to another. The EU agricultural price indices involve the index of producer prices of agricultural products and the index of purchase prices of the means of agricultural production. The purpose of agricultural price indices is to unveil trends in the prices of individual agricultural products and purchase prices of the means of agricultural production. Moreover, the objective of the applying statistics on agricultural prices is to make comparisons between member states and also for economic analyses. Absolute agricultural prices are needed for many model calculations and for the ascertainment of price elasticity. The means through which these objectives could be achieved are believed to be when the absolute prices are compared between the member states, and also, when the products for which the prices from the respective member state are to be recorded for economic relevance. These objectives are not always compatible and sometimes require some compromise. In this study, we evaluate the price indices of domestic agricultural production as a whole in the EU24, using the most accurate association model of the Categorical Data Analysis. Figures from the Eurostat office calculated on annual base year from 2005-2017 were used to analyse this study. Since the main focus is to have a better understanding of producer price indices, nominal total domestic agricultural production, the analysis of association table (ANOAS) is given in order to ascertain the percentage of the data which is covered by each model. We find and estimate the association model with the best fit and in conclusion we find out that the Row-Effects Association Model (R) has the best fit because it covers $93 \%$ of the data, thereby giving the best fit among all.
\end{abstract}

Index Terms - Association Model, Log-Linear and NonLinear Models, Agricultural Price Indices, Domestic Agricultural Production, EU24.

\section{INTRODUCTION}

One of the EU sources of economy is agriculture which is banded with a bilateral principle. The national indices of agricultural prices of member states may vary from the EU

Published on November 18, 2020.

Joel Chiadikobi Nwaubani, Fellow, Advance Higher Education London, UK.

(corresponding e-mail: joelinocool@yahoo.com)

Adanma Ngozi Ohia, Senior Lecturer, University of Portharcourt, Nigeria. Christiana Uzoma Ezechukwu, Assistant Chief Superintendent, Agricultural Development Programme (ADP), Nigeria.

Peace Opara, Confidential Secretary, Abia Secondary Education Management Board (SEMB), Nigeria.

Chinwe Adaugo Uzokwe, Lecturer, Michael Okpara University of Agriculture Umudike, Nigeria.

Uchechi Mgbafor Ezeji, Principal 11, Amuzukwu Girls' Secondary School, Nigeria. agricultural price indices as a result of their formula, base and field of observation. Price changes and price trends are fundamental for the measurement of absolute agricultural prices and agricultural price indices. Updates on the prices of products and the means of production are basically necessary to allow individual goals in the European Union agricultural principle to be decided, the indispensable measures to be taken and the effects of the principle to be observed.

To enable indices of groups of products or an overall index to be compiled from the various elementary indices of prices, weighting scheme is involved and the weighting problem is compounded in the case of an international index covering several countries. Thus, in principle, price indices can relate either to the production of agricultural products and the consumption of the means of production or to sales and purchases, but whichever combination is chosen the weights must be consistent with them. Agricultural products can be divided into two groups depending on their final use. These are: products sold outside the agricultural sector (for direct utilisation/utilisation after processing) or for export, and products to be sold within the agricultural sector as means of production, such as animal feeding stuffs, seeds or rearing animals.

The national authorities of the EU member states (National Statistical Offices and/or Ministries of Agriculture) are responsible for collecting absolute prices and calculating corresponding average prices for their country, as well as for calculating price indices and periodically updating the weights. The EU Working Group on agricultural accounts and prices normally meets once in a year in Luxembourg and are responsible for every question relating to agricultural price indices and absolute agricultural price statistics are discussed. Member States are required by the Eurostat to provide estimates of the output and input indices for the current year as a whole, 45 days before the end of the reference year. The selling prices of agricultural products and purchase prices of the means of production have a decisive influence on farmers' incomes. Therefore, it is useful to have indicators showing how agricultural revenue and expenditure are influenced by their price component [1].

\section{A. Agricultural Price Index and Statistics}

There are a wide range of methods by which estimates of a price or of an index may be generated from its current and past values and knowledge of the factors which may affect its future values. The EU Agricultural Price Indices are calculated for each Member State on the basis of the Laspeyres formula. The fixed weighting structure is 
representative of the base year. The use of Laspeyres indices is acceptable for practical reasons, as long as the period between two rebasements is not too long. The EU Agricultural Price Indices base level (output and input) are re-established for every 5 years [2].

$$
I^{t}=\frac{\sum_{i=1}^{k} p_{i}^{t} q_{i}^{0}}{\sum_{i=1}^{k} p_{i}^{0} q_{i}^{0}} \times 100=\sum_{i=1}^{k} \frac{p_{i}^{t}}{p_{i}^{0}} \times \frac{p_{i}^{0} q_{i}^{0}}{\sum_{i=1}^{k} p_{i}^{0} q_{i}^{0}} \times 100
$$

where $I$ - index (output or input).

$p$ - prices of products (or means of production)

$q$ - quantities sold of products (or quantities purchased of

means of production)

$i$ - product I (or means of production), $(i=1,2, \ldots \mathrm{k})$.

$t$ - observation period.

0 - base period.

Regardless of how we take the calculation, in practice there are in most cases several price quotations for a given product $i$. It is then necessary to calculate separately, on the basis of the available prices, a representative price relative for the product concerned. The Laspeyres formula can rarely be applied at this level, given that the weighting of the individual price series is not always known.

$$
\text { Replacing } \frac{p_{i}^{t}}{p_{i}^{0}} \text { by } R_{i}^{t} \text { in the formula set out in equation }
$$

(1), we derive the following formula:

$$
I^{t}=\sum_{i=1}^{k} R_{i}^{t} \times \frac{p_{i}^{0} q_{i}^{0}}{\sum_{i=1}^{k} p_{i}^{0} q_{i}^{0}} \times 100
$$

with $R_{i}^{t}$ being the elementary price index for the individual product $i$ (or means of production $i$ ) in observation period $t$ (i.e. the index of each product or means of production or the smallest grouping of them for which an index weight is used). In this formula the index is expressed in the form of the weighted average of the elementary indices with fixed base weights. The weights used are values (of sales or purchases) and not quantities. This formula allows one to adapt the calculation of the elementary indices to the different practical circumstances.

There are several possibilities for the calculation of the elementary price indices. The choice of the appropriate method depends essentially on the data available and on the degree of homogeneity of the products or means of production for which prices are recorded. As these circumstances might differ from one Member State to the other, a given elementary price index can be calculated using different methods.

\section{B. Quarterly versus Annual Indices and Treatment of Complementary Payments}

Agricultural price indices are calculated on a quarterly and an annual basis. Two options are involved for the calculation of the elementary quarterly indices. These are:

1. In cases where Member States collect API data on a monthly basis for their national purposes: starting from monthly indices, the quarterly indices are calculated as a weighted average of the monthly indices using the monthly weights.

2. Starting from quarterly prices. This option means that the Member State collects API data quarterly.

Whichever option is chosen for the calculation of the quarterly price indices, the prices should reflect the average price of all sales and purchases in the quarter.

Ideally the elementary price of a product should be the weighted mean of the elementary prices of the varieties of the product. Usually the weights are the quantities sold (or purchased in the case of input products). In any case the calculation of the elementary prices will depend on the availability of appropriate data for the weighting coefficients [1].

The elementary quarterly index of the price of a product is obtained by relating the quarterly price to the reference price, i.e. to the average price of the elementary product in the base year. The aggregated quarterly indices (for a group of products or for all products) are obtained by calculating the weighted average of the elementary indices of the group or of all products.

In some countries, only an annual price (and therefore an annual index) is available for certain products. An example of this is sugar beet, for which the annual index (or the index of the crop year) is used in the quarter(s) where the sales take place.

The annual indices can be obtained in two ways: (i) either as a simple or weighted arithmetic mean of the corresponding quarterly indices or (ii) on the basis of an annual mean price, possibly stemming from other data sources. Eurostat advocates the first method, which is used in most cases (weighted arithmetic mean for the output indices, simple arithmetic mean - as a rule - for the input indices).

Although, inconsistencies will arise if the components of annual, quarterly and base prices are not the same, however, in some Member States, producers receive a preliminary payment for certain products when selling the product and a complementary payment afterwards (possibly at the end or after the marketing year). Such complementary payments are part of the price and are not subsidies. Complementary (or final) payments should be included both in the annual and in the quarterly price indices. If at the time of calculating a given quarterly or annual index the amount of the complementary payment is not yet known, an estimate of this payment should be made. Once information on the complementary payment is available, the indices concerned should be revised.

\section{EU Calculation of Price Indices}

There are three ways used for the calculation of EU agricultural price indices for the European Union as a whole. This includes:

- Estimation of the API for the euro area with the national weight.

- Conversion of the weights of the non-Euro Member States into Euro.

- Calculation of the API for the EU with the Euro weights. 


\section{Treatment of Seasonal Discontinuity of Output Price} Series

When there are no transactions and therefore no prices for certain products in some quarters, the quarterly weight is zero and the related product should not be considered in the calculation of the quarterly aggregated index. This method reflects the actual market situation better and computation with fictitious prices of non-existing products can be avoided. On the other hand, the weighting scheme is different from quarter to quarter and as a result of this, quarterly price indices are only comparable between the corresponding quarters of different years.

\section{E. Treatment of Missing Observations}

Member States often fail to collect the intended number of representative prices, i.e., when there is weight, but the corresponding price data is not available), which leads to "missing observations". The procedures which are mainly followed by countries are:

(i) repetition of the last recorded price. In the case of a high rate of inflation, it may be appropriate to adjust the last recorded price.

(ii) repetition of the last recorded price by applying the normal seasonal pattern to it.

(iii) imputation of price changes on the basis of prices recorded on other markets for the same product.

\section{F. Seasonal Adjustment}

Many quarterly series of agricultural prices or price indices show a marked seasonal pattern. However no seasonally adjusted indices are calculated. Discussion is limited to comparisons with the corresponding period (quarter) of the previous year. Annual rates of change are thus calculated, and their interpretation is limited to an evaluation of the development of prices compared to their previous year's level.

\section{G. Choice of Representative Products and Considerations Related to Price Formation}

For each index heading (i.e. product or means of production or the smallest grouping of them for which an index weight) is used, a representative product must be selected whose price is to be monitored. The choice of these representative products is in the 'Member States' responsibility. It must be noted that the selected products should have an important share in the sales or purchases of the country in question so that the corresponding price series represent what the farmer actually receives (selling price) or pays (purchase price).

Differences in prices which are related, for example, to changes in quality, variations in the tonnage delivered, changes in the list of survey points or changes to any other price determining characteristic, must be eliminated by the Member States from the data forwarded, so that, as far as possible, only "pure" price variations are taken into account. The requirement regarding changes in quality applies to both output and input price indices. For industrial products (input) these changes are relatively frequent and major, and often represent an improvement in quality.

In order to avoid changes in prices, which might be caused by differences in quality, variety, packaging or terms of delivery etc., the selected products or services must be defined as to the quality, variety, weight, packaging and other characteristics which influence the prices.

Loosely defined specifications, or the use of unit values, may cause considerable "unit value bias", i.e. distortions due to the fact that for instance quality or variety changes are treated as price changes. For example, if in the case of the output price indices the unit value is taken for an agricultural product, an improvement of the quality and a tendency towards production of more highly priced varieties, would result in an increase of the product's average price (unit value). In the case of the input price indices, if the quality of a means of production, for example of ternary fertilisers, is loosely defined (i.e. 1-1-2) and an important quality characteristic such as the concentration of $\mathrm{N}-\mathrm{P}-\mathrm{K}$ is omitted from the definition, and the price observed is the average price (unit value) of the same product with different ratio of $\mathrm{N}-\mathrm{P}-\mathrm{K}$, then this average price may increase simply for the reason that the concentration of N-P$\mathrm{K}$ was increased between the two periods.

\section{H. Treatment of Quality Changes and Product Replacement}

It is sometimes necessary to change one of the selected products or means of production whose price is being used in the index. When this is done and a replacement product or means of production is selected there may be an associated change in quality or other price determining characteristics. This problem may be dealt with in several ways though, in the following, only the most important practices will be outlined.

Concerning the output price indices, changes in the definitions of the collected prices do not happen frequently. The effects of changes in quality on price may be readily quantified and the observed price of the item adjusted to allow for the change in quality. Also changes in other price determining characteristics (for instance in packaging, place of delivery, terms of payment etc.) in most cases can be valued and taken into account in a satisfactory way.

Changes in the definitions are more frequent in the case of the input price indices and concern chiefly the quality of the input. Frequent quality changes can occur particularly for compound feeding stuffs, fertilisers and, above all, agricultural tools and machinery. In the case where a defined input becomes unavailable, either generally or in a particular district, then a new product is chosen to replace the old one. If, however, an existing input is replaced by another of differing quality, then the problem is to assess how much of the price difference is attributable to differences in quality between the substitute and the replaced input. On this basis the price of the new product is adjusted to be in accordance with the quality level of the replaced product.

If, however, the change in quality is so great or difficult to quantify that no such adjustment can be made, then the old product is replaced by the new one. If both products existed in parallel during the period before substitution, then the price of the new product is recorded both for the period of substitution and the preceding period. The substitute product is linked into the index and a fictitious reference price is imputed for it on the basis of the rise in the elementary index of the replaced item from the base period. 


$$
p_{i}^{\prime(0)}=\frac{p_{i}^{\prime(t-1)}}{i_{i}^{(t-1)}} \times 100
$$

where: $p_{i}^{\prime(0)}$ imputed base price of the substitute product (or means of production) $\mathrm{i}$.

$p_{i}^{(t-1)}$ : price of substitute product $\mathrm{i}$ in the preceding period.

$i_{i}^{(t-1)}$ : elementary index in the preceding period.

If no reliable information on the actual price of the substitute product in the preceding period can be provided, then the price of the preceding period is estimated according to the price changes of similar products and a fictitious base price is calculated for the new product.

\section{Concepts of Marketing Agricultural Products}

Under the market price concept, the prices received from the sale for products and paid for the purchase of the means of production should be recorded without the deduction of taxes or levies and without the addition of subsidies. The treatment of taxes, levies and subsidies in the agricultural price statistics is the same as their treatment in the economic accounts for agriculture. As value added tax rates should be established so as not to affect income, Eurostat in principle records prices net of value added tax. It should be noted that this rule applies only to "deductible" value added tax. While value added tax paid when purchasing means of production is not refunded or compensated for all products and in all countries, non-deductible or non-compensable value added tax which is paid, is not deducted from recording prices.
The only exception to the principle of recording prices net of VAT concerns the value added tax on purchases of certain means of agricultural production for which there is no refund or compensation. Non-deductible or nonreimbursable VAT, which is paid in some EU countries for instance, on certain commodities like fuels in France, is not deducted from prices. It is the only one which is regarded as a component of purchase prices for the purpose of the EU Statistics on Agricultural Prices [1].

Furthermore, under the Economic Accounts for Agriculture, the production of wine and olive oil (exclusively using grapes and olives grown by the same holding) is considered as a characteristic agricultural activity. The production of wine or olive oil by units closely linked to agricultural holdings (e.g. agricultural cooperatives) is also treated as a characteristic agricultural activity. In contrast, the production of wine or olive oil by agro-food businesses is excluded.

\section{PROCESSING OF DATA}

The introduction and processing of observations (data) from table.1 below consists of producer price indices, nominal of the total domestic agricultural production as a whole for the period 2005-2017. The data used in this study were obtained from the Eurostat calculated on annual basis. The sub-indices were weighted by the values of sales in $2015=100$.

\begin{tabular}{|c|c|c|c|c|c|c|c|c|c|c|c|c|c|}
\hline Time/Geo & 2005 & 2006 & 2007 & 2008 & 2009 & 2010 & 2011 & 2012 & 2013 & 2014 & 2015 & 2016 & 2017 \\
\hline Belgium & 100 & 101,2 & 104,7 & 106,5 & 110,2 & 114,3 & 116,9 & 118,1 & 121,6 & 122,9 & 126,6 & 129,5 & 115,2 \\
\hline Czech Republic & 100 & 104 & 103,3 & 102,5 & 103,9 & 107,6 & 112,4 & 116,4 & 121,3 & 128,7 & 136,4 & 143,4 & 110,3 \\
\hline Denmark & 100 & 102,8 & 106,1 & 108,4 & 111,2 & 115,1 & 116,5 & 116,9 & 119,4 & 123,1 & 126,9 & 129,9 & 115,9 \\
\hline Germany & 100 & 101 & 102,8 & 104,9 & 107 & 110,4 & 111,8 & 111,6 & 113 & 114 & 117,1 & 118,4 & 111,8 \\
\hline Estonia & 100 & 104,4 & 116 & 121,1 & 121,5 & 134,7 & 156,6 & 167,7 & 181,2 & 200,2 & 223 & 244,2 & 145 \\
\hline Ireland & 100 & 108,3 & 120,9 & 131,2 & 145,3 & 158,9 & 178,3 & 186 & 194 & 204,7 & 215,5 & 226,9 & 168,2 \\
\hline Greece & 100 & 102,4 & 106,1 & 109,7 & 113,4 & 118,5 & 129,3 & 135,4 & 141,7 & 146,9 & 153,3 & 158,9 & 124,5 \\
\hline Spain & 100 & 102,4 & 106,4 & 111,1 & 116,4 & 122,3 & 130,2 & 134,1 & 138,5 & 143,4 & 148,9 & 153,9 & 126,7 \\
\hline France & 100 & 101,1 & 103,3 & 106,9 & 110,4 & 114,8 & 118,1 & 119,4 & 122,2 & 123,6 & 126,3 & 129,2 & 116,9 \\
\hline Italy & 100 & 100,7 & 102,6 & 104,1 & 106,1 & 109,9 & 112,3 & 112,3 & 113,6 & 113,7 & 115,9 & 117,4 & 111,9 \\
\hline Cyprus & 100 & 101,8 & 104,2 & 109,5 & 114,8 & 120,6 & 127,9 & 130,2 & 135,7 & 140,9 & 146,3 & 151,9 & 125,4 \\
\hline Latvia & 100 & 103,9 & 112,6 & 117,9 & 121,8 & 130,2 & 149,7 & 160,5 & 174,5 & 192,9 & 215,9 & 235,2 & 140,6 \\
\hline Lithuania & 100 & 105,1 & 114 & 122,5 & 120,7 & 125,7 & 143,3 & 158,1 & 169,7 & 182,5 & 196,2 & 209,9 & 134 \\
\hline Luxembourg & 100 & 101,5 & 107,5 & 114,5 & 124,2 & 134,7 & 143,3 & 145,3 & 150,6 & 156,5 & 166,2 & 173,7 & 138 \\
\hline Hungary & 100 & 101,3 & 106 & 111,1 & 115,8 & 121,8 & 132,2 & 137,7 & 144,4 & 150,5 & 156,4 & 160,2 & 126,7 \\
\hline Netherlands & 100 & 103,4 & 107,8 & 112,1 & 117,3 & 121,9 & 124,4 & 124,8 & 127,2 & 129,2 & 132,9 & 136,8 & 124,3 \\
\hline Austria & 100 & 102,6 & 104,5 & 108,2 & 111,8 & 115,6 & 117,5 & 118,8 & 121,7 & 124,2 & 128 & 131,3 & 116,5 \\
\hline Poland & 100 & 106,2 & 113,8 & 119,4 & 124,8 & 130,1 & 133,4 & 138,5 & 145,9 & 151 & 159,8 & 167,3 & 131,5 \\
\hline Portugal & 100 & 103,6 & 108 & 113,1 & 117,6 & 122,2 & 125,6 & 124,7 & 126,3 & 127 & 128,6 & 130,4 & 124,6 \\
\hline Slovenia & 100 & 103,7 & 108,8 & 113 & 119,1 & 124 & 131,7 & 135,2 & 141,1 & 146,8 & 154,5 & 161 & 127,3 \\
\hline Slovakia & 100 & 106,9 & 113,1 & 117,2 & 117,6 & 118,5 & 127,3 & 132,6 & 139,8 & 148,2 & 160,5 & 172,1 & 122,3 \\
\hline Finland & 100 & 103,7 & 110 & 115,7 & 120,2 & 126,2 & 131,7 & 134 & 139 & 143,1 & 150,9 & 155,5 & 129,6 \\
\hline Sweden & 100 & 101,3 & 103,7 & 107,5 & 112,4 & 117,2 & 120,9 & 122,9 & 128 & 131,7 & 137,5 & 142,1 & 118,5 \\
\hline United Kingdom & 100 & 102,8 & 105,9 & 109,4 & 112,7 & 117 & 122,2 & 125,5 & 129,6 & 132 & 135,7 & 139,3 & 119,8 \\
\hline
\end{tabular}


With the help of the Categorical Data Analysis program, we were able to process the data in table.1 above for the Price Indices of the total Domestic Agricultural Production in the EU24. Below are the values (prices) of all models under estimation. The statistics used to compare the association (correlation) of the various models are $\mathrm{X}^{2}$ (Pearson) Chi - Square and the Likelihood-Ratio Chi Square $\mathrm{G}^{2}$-probability ratio [3]. In continuation, we have the following results b below:

\section{A. Null Association-Independence Model (O)}

Goodness-Of-Fit Information

Pearson chi-square $=191.84564$

Likelihood-ratio chi-square $=191.56936$

Degrees of freedom $=276$

Index of dissimilarity $=0.02477$

Final iteration $=3$

Maximum deviation $=0.00000000$

B. Uniform Association Model (U)

Goodness-of-fit information

Pearson chi-square $=190.46406$

Likelihood-ratio chi-square $=190.06999$

Degrees of freedom $=275$

Index of dissimilarity $=0.02473$

Final iteration $=4$

Maximum deviation $=0.00007288$

\section{Row-Effects Association Model(R)}

Goodness-of-fit information

Pearson chi-square $=18.65966$

Likelihood-ratio chi-square $=18.66713$

Degrees of freedom $=253$

Index of dissimilarity $=0.00785$

Final iteration $=6$

Maximum deviation $=0.00009947$

D. Column-Effects Association Model(C)

Goodness-of-fit information

Pearson chi-square $=189.57769$

Likelihood-ratio chi-square $=189.44402$

Degrees of freedom $=264$

Index of dissimilarity $=0.02460$

Final iteration $=4$

Maximum deviation $=0.00000055$

E. Row-Column Effects Association Model I $(R+C)$

Goodness-of-fit information

Pearson chi-square $=18.23238$

Likelihood-ratio chi-square $=18.24477$

Degrees of freedom $=242$

Index of dissimilarity $=0.00788$

Final iteration $=6$

Maximum deviation $=0.00009843$

\section{F. Row-Column Effects Association Model Ii (Rc)}

Goodness-of-fit information

Pearson chi-square $=15.69197$

Likelihood-ratio chi-square $=15.70389$

Degrees of freedom $=242$

Index of dissimilarity $=0.00671$

Final iteration $=221$

Maximum deviation $=0.00098459$

\section{ASSOCIATION MODEL}

In the categorical data analysis system, we apply the methodology by considering six of the most commonly used association models. These are:

1. The model of Independence or null association model which is also symbolized by $(\mathrm{O})$ and holds that there is no relationship between the variables. The log-linear model is:

$$
\log \left(\mathrm{F}_{\mathrm{ij}}\right)=\lambda+\lambda_{\mathrm{A}(\mathrm{i})}+\lambda_{\mathrm{B}(\mathrm{j})}
$$

where $\log$ denotes the natural logarithm, $F_{i j}$ the expected frequencies under the independence model, $\lambda_{\mathrm{A}(\mathrm{i})}$ are the rows main effect and $\lambda \mathrm{B}_{(\mathrm{j})}$ are the columns main effect [4].

2. The Uniform association model, which is symbolized by $(\mathrm{U})$ in $\log$-linear form is:

$$
\log \left(\mathrm{F}_{\mathrm{ij}}\right)=\lambda+\lambda_{\mathrm{A}(\mathrm{i})}+\lambda_{\mathrm{B}(\mathrm{j})}+\varphi \chi_{\mathrm{i}} \mathrm{y}_{\mathrm{j}}
$$

where $\varphi$ is a single parameter for interaction and $\chi_{\mathrm{i}}, \mathrm{y}_{\mathrm{j}}$ are the scores for the row and column variables $(i=1, \ldots, \mathrm{I}, \mathrm{j}=1, \ldots, \mathrm{J})$ respectively.

3. The row effects model (R) where linear-by-linear interaction holds that

$$
\log \left(\mathrm{F}_{\mathrm{ij}}\right)=\lambda+\lambda_{\mathrm{A}(\mathrm{i})}+\lambda_{\mathrm{B}(\mathrm{j})}+\varphi \mu_{\mathrm{I}} \mathrm{y}_{\mathrm{j}}[5]
$$

where $y_{j}$ are fixed scores for the column variable $(j=1, \ldots, J)$ and $\mu_{\mathrm{I}}$ are unknown scores for the row variable $(i=1, \ldots, \mathrm{I})$.

4. The column effects model (C) is the same as the $\mathrm{R}$ model with a change in subscripts:

$$
\log \left(\mathrm{F}_{\mathrm{ij}}\right)=\lambda+\lambda_{\mathrm{A}(\mathrm{i})}+\lambda_{\mathrm{B}(\mathrm{j})}+\varphi v_{\mathrm{j}} \mathrm{X}_{\mathrm{I}}
$$

where $\mathrm{x}_{\mathrm{I}}$ are fixed scores for the row variable $(\mathrm{i}=1, \ldots, \mathrm{I})$ and $v_{\mathrm{j}}$ are unknown scores for the column variable $(\mathrm{j}=1, \ldots, \mathrm{J})$.

5. The model that allows both row and column effects in additive form is called the $\mathrm{R}+\mathrm{C}$ model [6]. The logfrequency version of the above model is:

$$
\log \left(F_{i j}\right)=\lambda+\lambda_{\mathrm{A}(i)}+\lambda_{\mathrm{B}(j)}+\sum_{K=1}^{I-1} \beta_{K} y_{j} Z_{A(K)}+\sum_{K=1}^{J-1} Y_{K} x_{i} Z_{B(K)}
$$

where $\chi_{\mathrm{i}}, \mathrm{y}_{\mathrm{j}}$ are the scores (as defined earlier), and $Z_{A(i)}$, $Z_{B(j)}$ denote to variables (dummy variables) for the row and column levels respectively.

6. The model, instead of additive row and column effects on the local odds ratios, has multiplicative effects called the $\mathrm{R} * \mathrm{C}$ model or model II, (Goodman, L.A., 1981a). The logmultiplicative model is:

$$
\log \left(\mathrm{F}_{\mathrm{ij}}\right)=\lambda+\lambda_{\mathrm{A}(\mathrm{i})}+\lambda_{\mathrm{B}(\mathrm{j})}+\varphi \mu_{\mathrm{I}} v_{\mathrm{j}}
$$

where the row score parameters $\mu_{\mathrm{I}}$ and column score parameters $v_{\mathrm{j}}$ are not known but are estimated in the data.

We aim at finding out the model that has the best fit among the 6 models used in our study, i.e. producer price indices, nominal of the total domestic agricultural production as a whole for the period 2005-2017. For this reason, first, we are going to examine the Index of 
Dissimilarity (L2), which shows that, the lesser the number, the more our model will give the best fit to match the data under consideration.

We analyze the six association model describe above, with the help of the categorical data analysis statistical programme [7]. We used the Pearson chi-squared $\left(\mathrm{X}^{2}\right)$ statistics, the likelihood-ratio chi-square $\left(\mathrm{G}^{2}\right)$ statistics and the index of dissimilarity which is equated by:

$$
D=\sum_{l j}\left|f_{i j} / n-F_{i j} / n\right| / 2
$$

where:

$f_{i j}$ are the observed frequencies

$F_{i j}$ are the expected frequencies (under the model)

Additionally, we have the following results as shown in the table below:

\begin{tabular}{lc}
\multicolumn{2}{c}{ TABLE2:INDEX OF DISSIMILARITY } \\
\hline \multicolumn{1}{c}{ Models } & $\begin{array}{c}\text { Index of } \\
\text { Dissimilarity (D) }\end{array}$ \\
\hline (a) Null Association-Independence Model (O) & 0.02477 \\
(b) Uniform Association Model (U) & 0.02473 \\
(c) Row-Effects Association Model (R) & 0.00785 \\
(d) Column-Effects Association Model (C) & 0.02460 \\
(e) Row+Columns Effects Association Model & 0.00788 \\
(R+C) & \\
(f) Row Column Effects Association Model & 0.00671 \\
(R*C) & \\
\hline
\end{tabular}

At first sight from Table 2 above, it shows that the Row Column Effects of the Association Model $\left(\mathrm{R}^{*} \mathrm{C}\right)$ adjusted better to the percentage of producer price indices, nominal of the total domestic agricultural production as a whole for the years under our study (having the lowest index of dissimilarity) with $\mathrm{D}=0.00671$.

Since we have models with similar lower ratio, we justify the model with the best fit to match both countries and years by calculating the Index BIC (Bayesian Information Criterion). In statistics, the Bayesian information criterion (BIC) or Schwarz criterion is a Criterion for model selection among a finite set of models; the model with the lowest BIC is preferred. It is based, in part, on the likelihood function. When fitting models, it is possible to increase the likelihood by adding parameters but doing so may result in over-fitting. The Bayesian Information Criterion (BIC) attempts to resolve this problem by introducing a penalty term for the number of parameters in the model and gives the best solution [8].

The formula for this calculation is:

$$
B I C=G^{2}-(D . F .) \log (n)
$$

Notations:

$\mathrm{G}^{2}=$ the likelihood-ratio chi-square statistics.

d.f. $=$ degrees of freedom of the models.

$\mathrm{n}=$ the size of the sample (39535.2).

$\log (n)=\log (39535.2)=10.5849467$.

When comparing a number of models, the model with the smallest index of BIC is assumed to be the best. So, we choose the models that have similar and lowest Index of Dissimilarity out of the six models. More precisely, we will consider the $3^{\text {rd }}, 5^{\text {th }}$ and $6^{\text {th }}$ models respectively.

Subsequently, the calculation is as follows:

$$
\begin{gathered}
3^{\text {rd }} \text { model: } \mathrm{BIC}=\mathrm{G}^{2}-(\text { D.F. }) \log (\mathrm{n})=18.66713-\left(253^{*}\right. \\
10.5849467)=-2659.32 \\
5^{\text {th }} \text { model: } \mathrm{BIC}=\mathrm{G}^{2}-(\text { D.F. }) \log (\mathrm{n})=18.24477-\left(242^{*}\right. \\
10.5849467)=-2543.31 \\
6^{\text {th }} \text { model: } \mathrm{BIC}=\mathrm{G}^{2}-(\text { D.F. }) \log (\mathrm{n})=15.69197-\left(242^{*}\right. \\
10.5849467)=-2545.87
\end{gathered}
$$

As we can see from the above calculations, the 3 rd model (Row-Effects Association Model (R)) finally accounts for the best fit from the results since it has the smallest index of BIC.

\section{A. Analysis of the Association Models}

In continuation, the association models are being tested to ascertain the accuracy, quality, or satisfactory fit of each model. Tests are done through the use of the likelihood-ratio chi-square $\left(\mathrm{G}^{2}\right)$ statistics and the Pearson chi-squared $\left(\mathrm{X}^{2}\right)$ distribution. In the case of the $\mathrm{X}^{2}$ distribution, the Statgraph programme will be of good help.

First, we observe that the likelihood-ratio chi-square statistic for the Independence model (O) which is $\mathrm{G}^{2}=191.56936$ with 276 degrees of freedom. The $95 \%$ reference point chi-square distribution is 316.309. This model has a satisfactory fit because the $\mathrm{X}^{2}$ distribution is bigger than the likelihood-ratio chi-square statistic $\mathrm{G}^{2}$.

Secondly, the Uniform association model has $\mathrm{G}^{2}=190.06999$ with 275 degrees of freedom. The $95 \%$ reference point chi-square distribution is 315.223. As it could be observed, this statistic is acceptable and has a satisfactory fit since the $\mathrm{X}^{2}$ distribution is greater than the likelihood-ratio chi-square statistic $\mathrm{G}^{2}$.

Also, the statistic $\mathrm{G}^{2}$ for the Row model $(\mathrm{R})$ is reduced dramatically for 18.66713 with 253 degrees of freedom. The $95 \%$ reference point chi-square distribution is 291.549 . The row model also has an accepted fit because the $\mathrm{X}^{2}$ distribution is much greater than the likelihood-ratio chisquare statistic $\mathrm{G}^{2}$.

The Column model (C) has $\mathrm{G}^{2}=189.44402$ with 264 degrees of freedom. The $95 \%$ reference point chi-square distribution is 303.398 which show even a better fit as we could observe that the $\mathrm{X}^{2}$ distribution is bigger than the likelihood-ratio chi-square statistic $\mathrm{G}^{2}$.

The statistics of the model $\mathrm{R}+\mathrm{C}$, that takes into account the effects for both Countries and the Years in additive form, is $\mathrm{G}^{2}=18.24477$ with 242 degrees of freedom. The $95 \%$ reference point chi-square distribution is 279.687 and has an acceptable fit since the $\mathrm{X}^{2}$ distribution is much bigger than the likelihood-ratio chi-square statistic $\mathrm{G}^{2}$.

Finally, the model RC, that is log multiplicative but not log-linear, the $\mathrm{G}^{2}$ Statistics has 15.69197 with 242 degrees of freedom. The $95 \%$ reference point chi-square distribution is 279.687. Also, this statistic is tremendously augmented just as the previous model because they have identical degrees of freedom, thereby showing an acceptable fit because the $\mathrm{X}^{2}$ distribution is very much larger than the likelihood-ratio chi-square statistic $\mathrm{G}^{2}$. 
By virtue of the index of dissimilarity of the models, the model $\mathrm{R}$ has the best fit. However, we have to find out the degree or level of effects on each model. To verify this, we will construct the analysis of association (ANOAS) table.

\section{B. Analysis of Association Table (ANOAS)}

The ANOAS table was given by [9]. In Table 3 below, the $\mathrm{X}^{2}$ is divided so that it can be used as two factor analysis of variance by making use of the $G^{2}(0)$ statistics for the base (zero) independence model which measures the total deviation of the variables. In other words, we can find the percentage of the baseline chi-squared $\mathrm{X}^{2}$ distribution, which have effects on each of the models on the phenomenon being studied.

\begin{tabular}{cccc}
\multicolumn{4}{c}{ TABLE3: ANALYSIS OF ASSOCIATION TABLE } \\
\hline Models & Likelihood-G $^{2}$ & $\begin{array}{c}\text { Degrees of } \\
\text { Freedom }\end{array}$ & $\begin{array}{c}\text { Index of } \\
\text { Dissimilarity }\end{array}$ \\
\hline O & 191.56936 & 276 & 0.02477 \\
U & 190.06999 & 275 & 0.02473 \\
R & 18.66713 & 253 & 0.00785 \\
C & 189.44402 & 264 & 0.02460 \\
R+C & 18.24477 & 242 & 0.00788 \\
RC & 15.70389 & 242 & 0.00671 \\
\hline
\end{tabular}

The analysis of association Table (ANOAS) in Table 3 above has the following differences of our models: $\mathrm{O}-\mathrm{U}$ is the overall or total effects of the models, U-R are the row effects model, R-RC are the row effects model which gives the effects of the column, and RC and the residuals of the models.

TABLE 4: DEGREE OR LEVEL OF EFFECTS ON EACH MODEL (UNIFORMITY)

\begin{tabular}{cccc}
\hline Model Effects & $\mathrm{G}^{2}$ Prices & D.F. & Percentage \\
\hline 1.General (O-U) & 1.49937 & 1 & $0.77 \%$ \\
2. Rows(U-R) & 171.40286 & 22 & $89.40 \%$ \\
3. Column-effects & & & \\
which gives the & 2.97516 & 11 & $1.54 \%$ \\
Row-effects (R-RC) & & & \\
4. Residual (RC) & 15.69197 & 242 & $8.19 \%$ \\
Total (O) & 191.56936 & 276 & $100.00 \%$ \\
\hline
\end{tabular}

From the ANOAS table in Table 4 above, we created the uniform association model (U) as shown, covers only $0.77 \%$ of the total baseline chi-squared $\mathrm{X}^{2}$ distribution. The Row model (R) accounts for a large percentage of $89.40 \%$, the Column model (C) covers a small percentage of $1.54 \%$ of the baseline chi-squared value. Furthermore, the RC effects (Residuals) are weaker because it accounts for only $8.19 \%$ of the baseline chi-squared value. We can also say that a very small percentage $(1.54 \%)$ is unsatisfactorily explained by the linear model on the column- effects, making it unreliable and unacceptable due to its poor fit as we could see above, i.e., the value of the Pearson chi-squared $\mathrm{X}^{2}$ distribution point for $95 \%$ confidence intervals are very much lower for the RC model.

Finally, we can also say that the percentage of $(191.56936-15.69197) / 191.56936=91.8 \%$ of the data explained the rate of the variation which is attributed to the null-independence has been measured from the model of $\mathrm{RC}$. This rate is quite satisfactory and we can say that the corresponding percentage of producer price indices, nominal of the total domestic agricultural production as a whole for the period 2005-2017in Belgium, Czech Republic,
Denmark, Germany, Estonia, Ireland, Greece, Spain, France, Italy, Cyrus, Latvia, Lithuania, Luxembourg, Hungary, Netherlands, Austria, Poland, Portugal, Slovenia, Slovakia, Finland, Sweden and United Kingdom, as seen from the data taken from the Eurostat, depended directly on the changes of the indices of the individual markets of each country and also from the years under our study (2005-2017).

IV. EVALUATION OF THE BEST MODEL

TABLE 5: EVALUATION OF THE BEST MODEL - ROW-EFFECTS ASSOCIATION MODEL (R)

\begin{tabular}{|c|c|c|c|c|}
\hline Years & Countries & Data & $\frac{\text { Prices of model }}{\underline{(0)}}$ & $\frac{\frac{\text { Prices of }}{\text { Model }}}{\text { (Row) }}$ \\
\hline 1 & 1 & 100.0000 & 90.3114 & 100.1572 \\
\hline 1 & 2 & 101.2000 & 93.1750 & 101.7968 \\
\hline 1 & 3 & 104.7000 & 97.5401 & 104.9505 \\
\hline 1 & 4 & 106.5000 & 101.5063 & 107.5304 \\
\hline 1 & 5 & 110.2000 & 105.2203 & 109.7093 \\
\hline 1 & 6 & 114.3000 & 110.3380 & 113.1984 \\
\hline 1 & 7 & 115.2000 & 113.8488 & 114.8895 \\
\hline 1 & 8 & 116.9000 & 117.1603 & 116.2602 \\
\hline 1 & 9 & 118.1000 & 120.6673 & 117.7066 \\
\hline 1 & 10 & 121.6000 & 125.6834 & 120.4781 \\
\hline 1 & 11 & 122.9000 & 130.8650 & 123.2339 \\
\hline 1 & 12 & 126.6000 & 137.6986 & 127.341 \\
\hline 1 & 13 & 129.5000 & 143.6855 & 130.4481 \\
\hline 2 & 1 & 100.0000 & 90.4632 & 95.2663 \\
\hline 2 & 2 & 104.0000 & 93.3316 & 97.6177 \\
\hline 2 & 3 & 103.3000 & 97.7040 & 101.465 \\
\hline 2 & 4 & 102.5000 & 101.6768 & 104.8094 \\
\hline 2 & 5 & 103.9000 & 105.3971 & 107.8077 \\
\hline 2 & 6 & 107.6000 & 110.5234 & 112.1461 \\
\hline 2 & 7 & 110.3000 & 114.0401 & 114.7523 \\
\hline 2 & 8 & 112.4000 & 117.3571 & 117.0711 \\
\hline 2 & 9 & 116.4000 & 120.8701 & 119.4969 \\
\hline 2 & 10 & 121.3000 & 125.8946 & 123.3108 \\
\hline 2 & 11 & 128.7000 & 131.0849 & 127.163 \\
\hline 2 & 12 & 136.4000 & 137.9300 & 132.4757 \\
\hline 2 & 13 & 143.4000 & 143.9269 & 101.3176 \\
\hline 3 & 1 & 100.0000 & 90.5846 & 136.818 \\
\hline 3 & 2 & 102.8000 & 93.4569 & 102.8371 \\
\hline 3 & 3 & 106.1000 & 97.8351 & 105.8798 \\
\hline 3 & 4 & 108.4000 & 101.8133 & 108.3359 \\
\hline 3 & 5 & 111.2000 & 105.5386 & 110.3818 \\
\hline 3 & 6 & 115.1000 & 110.6717 & 113.7385 \\
\hline 3 & 7 & 115.9000 & 114.1932 & 115.2817 \\
\hline 3 & 8 & 116.5000 & 117.5146 & 116.4995 \\
\hline 3 & 9 & 116.9000 & 121.0323 & 117.7895 \\
\hline 3 & 10 & 119.4000 & 126.0636 & 120.4 \\
\hline 3 & 11 & 123.1000 & 131.2608 & 122.9877 \\
\hline 3 & 12 & 126.9000 & 138.1151 & 126.9149 \\
\hline 3 & 13 & 129.9000 & 144.1201 & 129.836 \\
\hline
\end{tabular}




\begin{tabular}{|c|c|c|c|c|c|c|c|c|c|}
\hline 4 & 1 & 100.0000 & 86.4323 & 100.511 & 7 & 13 & 158.9000 & 158.4046 & 160.0114 \\
\hline 4 & 2 & 101.0000 & 89.1730 & 101.3832 & 8 & 1 & 100.0000 & 99.2108 & 99.8169 \\
\hline 4 & 3 & 102.8000 & 93.3505 & 103.7331 & 8 & 2 & 102.4000 & 102.3566 & 103.006 \\
\hline 4 & 4 & 104.9000 & 97.1464 & 105.4787 & 8 & 3 & 106.4000 & 107.1518 & 107.825 \\
\hline 4 & 5 & 107.0000 & 100.7009 & 106.8015 & 8 & 4 & 111.1000 & 111.5088 & 112.1689 \\
\hline 4 & 6 & 110.4000 & 105.5987 & 109.3642 & 8 & 5 & 116.4000 & 115.5889 & 116.196 \\
\hline 4 & 7 & 111.8000 & 108.9588 & 110.158 & 8 & 6 & 122.3000 & 121.2108 & 121.7293 \\
\hline 4 & 8 & 111.8000 & 112.1280 & 110.6286 & 8 & 7 & 126.7000 & 125.0677 & 125.4416 \\
\hline 4 & 9 & 111.6000 & 115.4844 & 111.1572 & 8 & 8 & 130.2000 & 128.7054 & 128.8839 \\
\hline 4 & 10 & 113.0000 & 120.2850 & 112.9135 & 8 & 9 & 134.1000 & 132.5581 & 132.4875 \\
\hline 4 & 11 & 114.0000 & 125.2441 & 114.6222 & 8 & 10 & 138.5000 & 138.0684 & 137.6857 \\
\hline 4 & 12 & 117.1000 & 131.7841 & 117.5459 & 8 & 11 & 143.4000 & 143.7606 & 142.9939 \\
\hline 4 & 13 & 118.4000 & 137.5139 & 119.5027 & 8 & 12 & 148.9000 & 151.2676 & 150.0245 \\
\hline 5 & 1 & 100.0000 & 122.3578 & 94.6296 & 8 & 13 & 153.9000 & 157.8444 & 156.0408 \\
\hline 5 & 2 & 104.4000 & 126.2376 & 101.5201 & 9 & 1 & 100.0000 & 90.5846 & 100.2242 \\
\hline 5 & 3 & 116.0000 & 132.1515 & 110.478 & 9 & 2 & 101.1000 & 93.4569 & 101.9029 \\
\hline 5 & 4 & 121.1000 & 137.5251 & 119.4801 & 9 & 3 & 103.3000 & 97.8351 & 105.0991 \\
\hline 5 & 5 & 121.5000 & 142.5570 & 128.6711 & 9 & 4 & 106.9000 & 101.8133 & 107.7229 \\
\hline 5 & 6 & 134.7000 & 149.4906 & 140.1366 & 9 & 5 & 110.4000 & 105.5386 & 109.9467 \\
\hline 5 & 7 & 145.0000 & 154.2473 & 150.129 & 9 & 6 & 114.8000 & 110.6717 & 113.4858 \\
\hline 5 & 8 & 156.6000 & 158.7338 & 160.3573 & 9 & 7 & 116.9000 & 114.1932 & 115.2242 \\
\hline 5 & 9 & 167.7000 & 163.4853 & 171.3687 & 9 & 8 & 118.1000 & 117.5146 & 116.6424 \\
\hline 5 & 10 & 181.2000 & 170.2813 & 185.1451 & 9 & 9 & 119.4000 & 121.0323 & 118.1376 \\
\hline 5 & 11 & 200.2000 & 177.3015 & 199.8976 & 9 & 10 & 122.2000 & 126.0636 & 120.9644 \\
\hline 5 & 12 & 223.0000 & 186.5600 & 218.0313 & 9 & 11 & 123.6000 & 131.2608 & 123.7776 \\
\hline 5 & 13 & 244.2000 & 194.6713 & 235.7554 & 9 & 12 & 126.3000 & 138.1151 & 127.9506 \\
\hline 6 & 1 & 100.0000 & 129.8003 & 107.8269 & 9 & 13 & 129.2000 & 144.1201 & 131.1215 \\
\hline 6 & 2 & 108.3000 & 133.9160 & 114.4973 & 10 & 1 & 100.0000 & 86.2320 & 100.3367 \\
\hline 6 & 3 & 120.9000 & 140.1897 & 123.328 & 10 & 2 & 100.7000 & 88.9663 & 101.1978 \\
\hline 6 & 4 & 131.2000 & 145.8901 & 132.0154 & 10 & 3 & 102.6000 & 93.1342 & 103.5336 \\
\hline 6 & 5 & 145.3000 & 151.2281 & 140.7191 & 10 & 4 & 104.1000 & 96.9212 & 105.2659 \\
\hline 6 & 6 & 158.9000 & 158.5835 & 151.6933 & 10 & 5 & 106.1000 & 100.4675 & 106.576 \\
\hline 6 & 7 & 168.2000 & 163.6295 & 160.8506 & 10 & 6 & 109.9000 & 105.3540 & 109.123 \\
\hline 6 & 8 & 178.3000 & 168.3888 & 170.0551 & 10 & 7 & 111.9000 & 108.7062 & 109.9046 \\
\hline 6 & 9 & 186.0000 & 173.4294 & 179.8769 & 10 & 8 & 112.3000 & 111.8681 & 110.3638 \\
\hline 6 & 10 & 194.0000 & 180.6387 & 192.353 & 10 & 9 & 112.3000 & 115.2168 & 110.8807 \\
\hline 6 & 11 & 204.7000 & 188.0860 & 205.5594 & 10 & 10 & 113.6000 & 120.0062 & 112.6219 \\
\hline 6 & 12 & 215.5000 & 197.9076 & 221.9175 & 10 & 11 & 113.7000 & 124.9538 & 114.3154 \\
\hline 6 & 13 & 226.9000 & 206.5122 & 237.5075 & 10 & 12 & 115.9000 & 131.4787 & 117.2202 \\
\hline 7 & 1 & 100.0000 & 99.5629 & 121.423 & 10 & 13 & 117.4000 & 137.1951 & 119.1604 \\
\hline 7 & 2 & 102.4000 & 102.7199 & 101.1364 & 11 & 1 & 100.0000 & 97.6871 & 98.8379 \\
\hline 7 & 3 & 106.1000 & 107.5321 & 106.2869 & 11 & 2 & 101.8000 & 100.7846 & 101.9075 \\
\hline 7 & 4 & 109.7000 & 111.9046 & 111.0064 & 11 & 3 & 104.2000 & 105.5062 & 106.5829 \\
\hline 7 & 5 & 113.4000 & 115.9991 & 115.4468 & 11 & 4 & 109.5000 & 109.7963 & 110.781 \\
\hline 7 & 6 & 118.5000 & 121.6410 & 97.6189 & 11 & 5 & 114.8000 & 113.8136 & 114.6591 \\
\hline 7 & 7 & 124.5000 & 125.5115 & 125.6211 & 11 & 6 & 120.6000 & 119.3492 & 120.0154 \\
\hline 7 & 8 & 129.3000 & 129.1621 & 129.5792 & 11 & 7 & 125.4000 & 123.1468 & 123.5686 \\
\hline 7 & 9 & 135.4000 & 133.0285 & 133.7293 & 11 & 8 & 127.9000 & 126.7287 & 126.8498 \\
\hline 7 & 10 & 141.7000 & 138.5584 & 139.5262 & 11 & 9 & 130.2000 & 130.5222 & 135.2786 \\
\hline 7 & 11 & 146.9000 & 144.2708 & 145.4788 & 11 & 10 & 135.7000 & 135.9479 & 130.2838 \\
\hline 7 & 12 & 153.3000 & 151.8044 & 153.2356 & 11 & 11 & 140.9000 & 141.5527 & 140.3726 \\
\hline
\end{tabular}




\begin{tabular}{|c|c|c|c|c|}
\hline 11 & 12 & 146.3000 & 148.9444 & 147.147 \\
\hline 11 & 13 & 151.9000 & 155.4202 & 152.9157 \\
\hline 12 & 1 & 100.0000 & 118.7215 & 93.5177 \\
\hline 12 & 2 & 103.9000 & 122.4860 & 100.0653 \\
\hline 12 & 3 & 112.6000 & 128.2242 & 108.6105 \\
\hline 12 & 4 & 117.9000 & 133.4381 & 117.1539 \\
\hline 12 & 5 & 121.8000 & 138.3205 & 125.8365 \\
\hline 12 & 6 & 130.2000 & 145.0480 & 136.6916 \\
\hline 12 & 7 & 140.6000 & 149.6633 & 146.0561 \\
\hline 12 & 8 & 149.7000 & 154.0165 & 155.5996 \\
\hline 12 & 9 & 160.5000 & 158.6268 & 165.8502 \\
\hline 12 & 10 & 174.5000 & 165.2208 & 178.7151 \\
\hline 12 & 11 & 192.9000 & 172.0325 & 192.4516 \\
\hline 12 & 12 & 215.9000 & 181.0157 & 209.3618 \\
\hline 12 & 13 & 235.2000 & 188.8860 & 225.7901 \\
\hline 13 & 1 & 100.0000 & 114.2293 & 96.6606 \\
\hline 13 & 2 & 105.1000 & 117.8514 & 102.3651 \\
\hline 13 & 3 & 114.0000 & 123.3725 & 109.9646 \\
\hline 13 & 4 & 122.5000 & 128.3890 & 117.3952 \\
\hline 13 & 5 & 120.7000 & 133.0867 & 124.7995 \\
\hline 13 & 6 & 125.7000 & 139.5597 & 134.1716 \\
\hline 13 & 7 & 134.0000 & 144.0004 & 141.8898 \\
\hline 13 & 8 & 143.3000 & 148.1888 & 149.6072 \\
\hline 13 & 9 & 158.1000 & 152.6247 & 157.8239 \\
\hline 13 & 10 & 169.7000 & 158.9692 & 168.318 \\
\hline 13 & 11 & 182.5000 & 165.5231 & 179.3921 \\
\hline 13 & 12 & 196.2000 & 174.1664 & 193.1488 \\
\hline 13 & 13 & 209.9000 & 181.7389 & 206.1637 \\
\hline 14 & 1 & 100.0000 & 106.5987 & 100.7733 \\
\hline 14 & 2 & 101.5000 & 109.9787 & 104.9831 \\
\hline 14 & 3 & 107.5000 & 115.1310 & 110.9409 \\
\hline 14 & 4 & 114.5000 & 119.8125 & 116.5093 \\
\hline 14 & 5 & 124.2000 & 124.1963 & 121.8414 \\
\hline 14 & 6 & 134.7000 & 130.2369 & 128.8588 \\
\hline 14 & 7 & 138.0000 & 134.3810 & 134.0529 \\
\hline 14 & 8 & 143.3000 & 138.2896 & 139.043 \\
\hline 14 & 9 & 145.3000 & 142.4292 & 144.2915 \\
\hline 14 & 10 & 150.6000 & 148.3498 & 151.3806 \\
\hline 14 & 11 & 156.5000 & 154.4659 & 158.7137 \\
\hline 14 & 12 & 166.2000 & 162.5319 & 168.1027 \\
\hline 14 & 13 & 173.7000 & 169.5985 & 176.5088 \\
\hline 15 & 1 & 100.0000 & 101.0199 & 98.1049 \\
\hline 15 & 2 & 101.3000 & 104.2230 & 101.7879 \\
\hline 15 & 3 & 106.0000 & 109.1056 & 107.1273 \\
\hline 15 & 4 & 111.1000 & 113.5421 & 112.047 \\
\hline 15 & 5 & 115.8000 & 117.6965 & 116.6987 \\
\hline 15 & 6 & 121.8000 & 123.4210 & 122.9184 \\
\hline 15 & 7 & 126.7000 & 127.3481 & 127.3533 \\
\hline 15 & 8 & 132.2000 & 131.0522 & 131.5572 \\
\hline 15 & 9 & 137.7000 & 134.9751 & 135.9683 \\
\hline 15 & 10 & 144.4000 & 140.5860 & 142.0688 \\
\hline
\end{tabular}

\begin{tabular}{|c|c|c|c|c|}
\hline 15 & 11 & 150.5000 & 146.3820 & 109.0226 \\
\hline 15 & 12 & 156.4000 & 154.0258 & 156.4826 \\
\hline 15 & 13 & 160.2000 & 160.7226 & 163.6399 \\
\hline 16 & 1 & 100.0000 & 94.8279 & 103.5268 \\
\hline 16 & 2 & 103.4000 & 97.8347 & 105.4837 \\
\hline 16 & 3 & 107.8000 & 102.4181 & 109.0226 \\
\hline 16 & 4 & 112.1000 & 106.5826 & 111.9809 \\
\hline 16 & 5 & 117.3000 & 110.4824 & 114.5346 \\
\hline 16 & 6 & 121.9000 & 115.8560 & 118.4717 \\
\hline 16 & 7 & 124.3000 & 119.5424 & 120.5411 \\
\hline 16 & 8 & 124.4000 & 123.0194 & 122.2831 \\
\hline 16 & 9 & 124.8000 & 126.7019 & 124.1129 \\
\hline 16 & 10 & 127.2000 & 131.9688 & 127.3517 \\
\hline 16 & 11 & 129.2000 & 137.4096 & 130.5893 \\
\hline 16 & 12 & 132.9000 & 144.5849 & 135.2778 \\
\hline 16 & 13 & 136.8000 & 150.8712 & 138.9238 \\
\hline 17 & 1 & 100.0000 & 91.1006 & 100.8607 \\
\hline 17 & 2 & 102.6000 & 93.9892 & 102.5395 \\
\hline 17 & 3 & 104.5000 & 98.3924 & 105.7447 \\
\hline 17 & 4 & 108.2000 & 102.3933 & 108.3734 \\
\hline 17 & 5 & 111.8000 & 106.1398 & 110.5993 \\
\hline 17 & 6 & 115.6000 & 111.3021 & 114.1476 \\
\hline 17 & 7 & 116.5000 & 114.8437 & 115.8841 \\
\hline 17 & 8 & 117.5000 & 118.1840 & 117.2984 \\
\hline 17 & 9 & 118.8000 & 121.7218 & 118.7897 \\
\hline 17 & 10 & 121.7000 & 126.7817 & 121.6196 \\
\hline 17 & 11 & 124.2000 & 132.0085 & 124.4351 \\
\hline 17 & 12 & 128.0000 & 138.9018 & 128.617 \\
\hline 17 & 13 & 131.3000 & 144.9410 & 131.7908 \\
\hline 18 & 1 & 100.0000 & 104.5165 & 103.5245 \\
\hline 18 & 2 & 106.2000 & 107.8305 & 107.0882 \\
\hline 18 & 3 & 113.8000 & 112.8822 & 112.367 \\
\hline 18 & 4 & 119.4000 & 117.4722 & 117.1743 \\
\hline 18 & 5 & 124.8000 & 121.7704 & 121.6722 \\
\hline 18 & 6 & 130.1000 & 127.6930 & 127.7719 \\
\hline 18 & 7 & 131.5000 & 131.7561 & 131.9842 \\
\hline 18 & 8 & 133.4000 & 135.5884 & 135.9313 \\
\hline 18 & 9 & 138.5000 & 139.6471 & 140.067 \\
\hline 18 & 10 & 145.9000 & 145.4521 & 145.9117 \\
\hline 18 & 11 & 151.0000 & 151.4487 & 151.9005 \\
\hline 18 & 12 & 159.8000 & 159.3572 & 159.7512 \\
\hline 18 & 13 & 167.3000 & 166.2857 & 166.5561 \\
\hline 19 & 1 & 100.0000 & 94.1966 & 105.04 \\
\hline 19 & 2 & 103.6000 & 97.1834 & 106.6665 \\
\hline 19 & 3 & 108.0000 & 101.7362 & 109.8753 \\
\hline 19 & 4 & 113.1000 & 105.8730 & 112.4782 \\
\hline 19 & 5 & 117.6000 & 109.7468 & 114.6574 \\
\hline 19 & 6 & 122.2000 & 115.0847 & 118.2009 \\
\hline 19 & 7 & 124.6000 & 118.7465 & 119.8623 \\
\hline 19 & 8 & 125.6000 & 122.2004 & 121.1867 \\
\hline 19 & 9 & 124.7000 & 125.8584 & 122.5875 \\
\hline
\end{tabular}




\begin{tabular}{|c|c|c|c|c|}
\hline 19 & 10 & 126.3000 & 131.0902 & 125.3647 \\
\hline 19 & 11 & 127.0000 & 136.4947 & 128.1206 \\
\hline 19 & 12 & 128.6000 & 143.6223 & 132.2753 \\
\hline 19 & 13 & 130.4000 & 149.8667 & 135.3848 \\
\hline 20 & 1 & 100.0000 & 101.1473 & 100.3181 \\
\hline 20 & 2 & 103.7000 & 104.3545 & 103.7507 \\
\hline 20 & 3 & 108.8000 & 109.2433 & 108.8433 \\
\hline 20 & 4 & 113.0000 & 113.6854 & 113.4772 \\
\hline 20 & 5 & 119.1000 & 117.8451 & 117.8097 \\
\hline 20 & 6 & 124.0000 & 123.5768 & 123.691 \\
\hline 20 & 7 & 127.3000 & 127.5089 & 127.7434 \\
\hline 20 & 8 & 131.7000 & 131.2176 & 131.5374 \\
\hline 20 & 9 & 135.2000 & 135.1455 & 135.5124 \\
\hline 20 & 10 & 141.1000 & 140.7634 & 141.1388 \\
\hline 20 & 11 & 146.8000 & 146.5667 & 146.9024 \\
\hline 20 & 12 & 154.5000 & 154.2202 & 154.464 \\
\hline 20 & 13 & 161.0000 & 160.9254 & 161.0115 \\
\hline 21 & 1 & 100.0000 & 101.7483 & 99.6071 \\
\hline 21 & 2 & 106.9000 & 104.9746 & 103.2206 \\
\hline 21 & 3 & 113.1000 & 109.8924 & 108.5028 \\
\hline 21 & 4 & 117.2000 & 114.3609 & 113.3476 \\
\hline 21 & 5 & 117.6000 & 118.5453 & 117.9095 \\
\hline 21 & 6 & 118.5000 & 124.3110 & 124.0424 \\
\hline 21 & 7 & 122.3000 & 128.2665 & 128.3614 \\
\hline 21 & 8 & 127.3000 & 131.9972 & 132.4371 \\
\hline 21 & 9 & 132.6000 & 135.9485 & 136.711 \\
\hline 21 & 10 & 139.8000 & 141.5997 & 142.6708 \\
\hline 21 & 11 & 148.2000 & 147.4375 & 148.7927 \\
\hline 21 & 12 & 160.5000 & 155.1365 & 156.7632 \\
\hline 21 & 13 & 172.1000 & 161.8816 & 163.7337 \\
\hline 22 & 1 & 100.0000 & 100.7467 & 102.452 \\
\hline 22 & 2 & 103.7000 & 103.9412 & 105.5513 \\
\hline 22 & 3 & 110.0000 & 108.8106 & 110.3077 \\
\hline 22 & 4 & 115.7000 & 113.2351 & 114.5629 \\
\hline 22 & 5 & 120.2000 & 117.3783 & 118.4807 \\
\hline 22 & 6 & 126.2000 & 123.0873 & 123.9185 \\
\hline 22 & 7 & 129.6000 & 127.0038 & 127.4876 \\
\hline 22 & 8 & 131.7000 & 130.6978 & 130.7706 \\
\hline 22 & 9 & 134.0000 & 134.6102 & 134.2058 \\
\hline 22 & 10 & 139.0000 & 140.2058 & 139.242 \\
\hline 22 & 11 & 143.1000 & 145.9861 & 144.3723 \\
\hline 22 & 12 & 150.9000 & 153.6093 & 151.2215 \\
\hline 22 & 13 & 155.5000 & 160.2880 & 157.0271 \\
\hline 23 & 1 & 100.0000 & 93.7109 & 98.6955 \\
\hline 23 & 2 & 101.3000 & 96.6823 & 101.1301 \\
\hline 23 & 3 & 103.7000 & 101.2117 & 105.1143 \\
\hline 23 & 4 & 107.5000 & 105.3272 & 108.5775 \\
\hline 23 & 5 & 112.4000 & 109.1810 & 111.682 \\
\hline 23 & 6 & 117.2000 & 114.4913 & 116.1746 \\
\hline 23 & 7 & 118.5000 & 118.1343 & 118.8728 \\
\hline 23 & 8 & 120.9000 & 121.5704 & 121.2731 \\
\hline
\end{tabular}

\begin{tabular}{lcccc}
\hline 23 & 9 & 122.9000 & 125.2095 & 123.7841 \\
23 & 10 & 128.0000 & 130.4144 & 127.7331 \\
23 & 11 & 131.7000 & 135.7910 & 131.7216 \\
23 & 12 & 137.5000 & 142.8818 & 137.2227 \\
23 & 13 & 142.1000 & 149.0941 & 141.7186 \\
24 & 1 & 100.0000 & 94.2087 & 100.3755 \\
24 & 2 & 102.8000 & 97.1959 & 102.6654 \\
24 & 3 & 105.9000 & 101.7493 & 106.5172 \\
24 & 4 & 109.4000 & 105.8867 & 109.8275 \\
24 & 5 & 112.7000 & 109.7610 & 112.7634 \\
24 & 6 & 117.0000 & 115.0995 & 117.0874 \\
24 & 7 & 119.8000 & 118.7618 & 119.5901 \\
24 & 8 & 122.2000 & 122.2162 & 121.7842 \\
24 & 9 & 125.5000 & 125.8746 & 124.081 \\
24 & 10 & 129.6000 & 131.1071 & 127.8079 \\
24 & 11 & 132.0000 & 136.5123 & 131.5602 \\
24 & 12 & 135.7000 & 143.6408 & 136.8068 \\
24 & 13 & 139.3000 & 149.8860 & 141.0334 \\
\hline
\end{tabular}

${ }^{1} \mathrm{f}_{\mathrm{ij}}$ Expected frequencies of the independence model.

${ }^{2} \mathrm{~F}_{\mathrm{ij}}$ Expected frequencies of the model R.

From Table 5 above, it is clearly seen that the prices (value) of the Row-Effects Association Model (R) fully fitted to the data under our study.

\section{LOGARITHMS FOR THE COLUMN-EFFECTS ASSOCIATION MODEL}

The Row-Effects Association Model (R) is as follows:

Belgium: $\hat{\tau}_{1}=-\ln (0.98314)=-0.01715$

Czech Republic: $\hat{\tau}_{2}=-\ln (0.99118)=-0.00904$

Denmark: $\hat{\tau}_{3}=-\ln (0.9818)=-0,01918$

Germany: $\hat{\tau}_{4}=-\ln (0.97570)=-0.02429$

Estonia: $\hat{\tau}_{5}=-\ln (1.03774)=0.039221$

Ireland: $\hat{\tau}_{6}=-\ln (1.02714)=0.076961$

Greece: $\hat{\tau}_{7}=-\ln (1.00216)=0.001998$

Spain: $\hat{\tau}_{8}=-\ln (0.99821)=-0.002$

France: $\hat{\tau}_{9}=-\ln (0.98351)=-0.1715$

Italy: $\hat{\tau}_{10}=-\ln (0.97561)=-0.02429$

Cyprus: $\hat{\tau}_{11}=-\ln (0.99735)=-0.003$

Latvia: $\hat{\tau}_{12}=-\ln (1.03503)=0.034401$

Lithuania: $\hat{\tau}_{13}=-\ln (2.251785)=-0.812$

Luxembourg: $\hat{\tau}_{14}=-\ln (1.00771)=0.007968$

Hungary: $\hat{\tau}_{15}=-\ln (1.00362)=0.004$

Netherlands: $\hat{\tau}_{16}=-\ln (0.98559)=-0.0141$

Austria: $\hat{\tau}_{17}=-\ln (0.98341)=-0.01715$

Poland: $\hat{\tau}_{18}=-\ln (1.0006)=0.0006$

Portugal: $\hat{\tau}_{19}=-\ln (0.98228)=-0.01816$

Slovenia: $\hat{\tau}_{20}=-\ln (1.0004)=0.0004$

Slovakia: $\hat{\tau}_{21}=-\ln (1.0024)=0.002397$

Finland: $\hat{\tau}_{22}=-\ln (0.99657)=-0.003$ 
Sweden: $\hat{\tau}_{23}=-\ln (0.99117)=-0.00887$

UK: $\hat{\tau}_{24}=-\ln (0.98937)=-0.01069$

\section{RESEARCH FINDINGS \& COMPARISON OF THE PRODUCER PRICE INDICES, NOMINAL OF THE TOTAL DOMESTIC AGRICULTURAL PRODUCTION AS A WHOLE}

We try to compare some EU countries under our study to ascertain the variations within the producer price indices, nominal of the total domestic agricultural production as a whole for the period 2005-2017.

For instance, comparing Greece with Spain, we see that $\hat{\tau}_{7}-\hat{\tau}_{8}=0.004, \exp (0.004)=1.004$. It could be seen that Greece has 1,004 higher prices indices of domestic products than Spain.

In the case of Latvia and the Lithuania, we find that $\hat{\tau}_{12}$ $\hat{\tau}_{13}=0.0010685, \exp (0,7604)=1,010742$. This means that Latvia has 1.01 higher prices indices of domestic products than Lithuania.

Even among the advanced countries of Europe, we could observe the differences in the producer price indices.

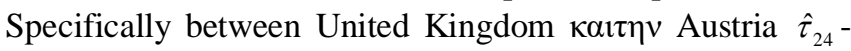
$\hat{\tau}_{17}=0.0065, \exp (0.0065)=1.0065$, we find out that the United Kingdom has 1.0065 times higher price indices of domestic products than Austria.

Also, comparing the differences in the producer price between Germany and the United Kingdom, we have: $\hat{\tau}_{4}$ $\hat{\tau}_{24}=0.0136$ and $\exp (0.0136)=2.736008$, it means that Germany's prices indices of domestic products were higher with 2.736008 greater than the United Kingdom.

Furthermore, in the case of Belgium and Germany, Belgium: $\hat{\tau}_{1}-\hat{\tau}_{4}=0.01$, and $\exp (0.01)=1.0101$. We could observe that Belgium had a minimal difference with Germany in the producer price indices of the total agricultural products.

By comparing two Central European EU member states like, Czech Republic and Slovakia we have: $\hat{\tau}_{2}-\hat{\tau}_{21}=$ -0.011437 , and $\exp (-0.011437)=0.9886$, it means that Czech Republic had 0.9866 producer price indices slightly lower than that of Slovakia in relation to the of total agricultural production as a whole.

Finally, comparing two Scandinavian countries like Finland and Sweden, we see that: $\hat{\tau}_{22}-\hat{\tau}_{23}=0.0$, $\exp (0.01187)=0.9882$. In other words, Finland also had 0.9882 producer price indices slightly lower than Sweden as regards to the total agricultural production as a whole

\section{SUMMARY}

The comparability of agricultural products and means of production for which price indices are recorded depends on a certain number of specific characteristics associated with the procedure for recording the prices and their statistical processing. Based on the fact that the structure of production varies from one country to another, it is left to the discretion of the member states which representative price indices should appear in the subgroup in their own case. By comparisons on the EU agricultural price indices, the structures of the weights with respect to products and means of production reflect the value of the sales and purchases in each country during the base year. The weights therefore differ from one country to another and this obviously has an effect on trends in the aggregate indices.

Under the EAA, the production of wine and olive oil (exclusively using grapes and olives grown by the same holding) is considered as a characteristic agricultural activity. The production of wine or olive oil by units closely linked to agricultural holdings (e.g. agricultural cooperatives) is also treated as a characteristic agricultural activity. In contrast, the production of wine or olive oil by agro-food businesses is excluded.

Furthermore, the description of the price indices for commodities such as fuels does not provide all the indications desired on the subsidies existing in several countries, for example, the non-deductible or nonrefundable VAT, which exist on fuels in France, is not deducted from prices. The granting of subsidies mostly depends on certain conditions which can change in the course of time and not all farmers of a country always benefit from them. For this reason, it is almost impossible to draw up general rules for handling these subsidies. All these characteristics could have an influence on the price level of a specific product or means of production. Thus, strict comparability between Member States would require that there should be fairness for all the prices collected in individual countries. Although, a general agreement has been achieved on the marketing stage, in reality, full harmonisation of all the price-determining characteristics (some of the marketing conditions, treatment of taxes, levies and subsidies) between Member States has not been feasible [10].

\section{CONCLUSION}

Agricultural prices are recorded at points which are as close as possible to those of the transactions which the farmer actually undertakes. This means that product prices are being recorded at the first marketing stage so as to best indicate the actual producer prices received by farmers. Similarly, the prices paid by farmers for their means of production are recorded at the last marketing stage, that at which the items arrive on the farm, so as to best indicate the purchase prices paid by farmers.

The field of observation for a price index covers all the goods and services for which it is desired to measure the price trends. However, there are several concepts which can be distinguished, and these concepts are characterised by a different coverage of agricultural products. Agricultural products are divided into two groups depending on their end use such as:

$\checkmark$ products sold outside the agricultural sector (for direct utilisation or utilisation after processing) or for export.

$\checkmark$ products to be sold within the agricultural sector as means of production, such as animal feeding stuffs, seeds, or rearing animals.

Based on the results of our research, we can see that all the six association models show satisfactory fit. However, 
the prices indices of the row-effects association model (R) fully fitted best among all to our data. The producer price indices were directly dependent on the changes of the indices of the individual markets, i.e., the price index of domestic and foreign market producers.

Specifically, the price of prices indices of domestic products is affected by a number of factors. These could be as a result of:

$>$ The standard of living of each country; every country can prosper if its citizens are productive and do not display behaviours that hinder development such as corruption and poor work ethic [11].

$>$ Diversification of investments, public spending on agricultural development and taxation [12].

$>$ The degree of utilisation of the workforce, which is directly related to efficiency in the production of goods and services [13].

$>$ It is a well-known proposition in economics that monopoly price will be higher (and output lower) than price (and output) under competitive conditions. This enables a monopolist to earn higher - equivalent to the loss in consumers' surplus from not producing the competitive output at the competitive price [14].

$>$ When a producer would persuade government (politicians, bureaucrats) to establish a monopoly in an industry by raising barriers to entry (requiring new entrants to obtain permission from the government to set up in that industry) then he would benefit since, as we have seen, producer's surplus is greater under monopoly than under competition [15].

$>$ Government intervention (the efforts of public officials to react to such monopoly [16].

$>$ Third party distortions caused by monopoly activity, for instance, in a country with exchange controls, commodities may only be imported with an import licence [17].

$>$ Several other factors which are difficult to be determined in each country.

To evaluate the degree of correlation (association) between these countries and years, we use the $\theta$ of the second model, (the uniform association model which is symbolised by (U) for calculation. We should mention that $\Theta$ (Theta in Greek language), which is 0.99976, i.e. approximately equal to 1 , unveil that we have independence between the variables. More specifically, the innate correlation index in log-linear form is equal to:

$$
\log \left(\mathrm{F}_{\mathrm{ij}}\right)=\lambda+\lambda_{\mathrm{A}(\mathrm{i})}+\lambda_{\mathrm{B}(\mathrm{j})}+\varphi \chi_{\mathrm{i}} \mathrm{y}_{\mathrm{j}}
$$

where $\varphi$ is a single parameter for interaction.

The parameter of interaction $\varphi$ is:

$$
\begin{gathered}
\log \theta=\log (0.08906) \\
\varphi=\log (0.99976)=-0.00024 \\
\left|\varphi^{1 / 2}\right|=\sqrt{ } 0.00024=0.015491933 \\
\Phi^{1 / 2}=-\sqrt{ } 0.00026=-0.015491933
\end{gathered}
$$

The general conclusion based on our study is that there is a correlation (association) in the price indices of domestic agricultural production in EU24. In the majority of member states, national indices of agricultural prices differ from the EU agricultural price indices. This could be as a result of their base, formula or field of observation, thus, we can conclude that the producer price indices on domestic products were depended directly on the changes of the indices of the individual markets, i.e., the Price Index (PPI) of domestic and foreign market producers, but without very much fluctuation.

\section{ACKNOWLEDGEMENT}

Many thanks to Dr Antonia Gkouma, resident doctor in Thoracic and Cardiac Surgery at Royal Brompton Hospital London, UK not only for the selection of this challenging and innovative theme that subsequent kept me beneficial from my numerous skill set, and allow me to incorporate the entirety of my strengths and abilities, contributing wholesomely to my continuing professional development (CPD), but also for the support and encouragement to the execution of this project.

Also, I would like to thank my co-authors, Ohia, Adanma Ngozi - Senior Lecturer, University of Portharcourt, River state, Nigeria; Ezechukwu, Christiana Uzoma - Assistant Chief Superintendent, Agricultural Development Programme (ADP), Umuahia, Abia State Nigeria; Opara Peace - Confidential Secretary, Abia Secondary Education Management Board (SEMB), Umuahia, Abia State, Nigeria; Uzokwe Chinwe Adaugo - Lecturer 1, Michael Okpara University of Agriculture Umudike, Umuahia, Abia State, Nigeria, and Ezeji, Uchechi Mgbafor - Principal 11, Amuzukwu Girls' Secondary School, Umuahia, Abia State, Nigeria for their warm support and contributions.

Together, I would like to thank everyone who helped in one way or the other particularly, Mrs Angelina Nnaduo, Mrs Blessing Chinwe Nwaubani, Mrs Faith Chikodi Nnaduo, Miss Goodness Ihechiluru Nwaubani, Miss Irene Nnenna Iroeche, Miss Blessing Chihurumnanya Ogbonna, Mrs Maureen Mgbechi Chikezie, Mrs Charity Nkemhuruanya Alozie Duruji, Mrs Magdalene Zelka Bozidis, Mrs Christina Patricia, Mrs Benetia Sirgoudi, Mr Victor Chinonso Nwoko, Mr Victor Obinna Iwundu and Mr. Stamatis Bozidis.

\section{REFERENCES}

[1] Handbook for EU Agricultural Price Statistics, Version 2.1., November 2015

[2] European Commission - Agriculture and Rural Development (2006), Rural Development 2007-2013; Handbook on common monitoring and evaluation framework - Guidance document. Brussels: European Commission.

[3] Eliason P. Scott-Clifford Clogg (1990), Categorical Data Analysis (CDAS).

[4] Diewert, W. Erwin, (1995). Axiomatic and Economic Approaches to Elementary Price indexes. NBER working paper 5104.

[5] Goodman, L.A., (1979a). Multiple Models for the Analysis of Occupational Mobility Tables \&Other Kinds of Cross-Classification Tables, “American Journal of Sociology”, 84:804-819.

[6] Goodman, L.A., (1979b). Multiple Models for the Analysis of Occupational Mobility Tables and Other Kinds of CrossClassification Tables. "American Journal of Sociology".

[7] Clogg, C.C. (1990), Analysis of Association (ANOAS) Program. 
[8] Schwarz, Gideon E. (1978). Annals of Statistics, Estimating the Dimension of a Model; Volume 6, Number 2, pp. 461-464.

[9] Goodman, L.A., (1981b). Association Models and Canonical Correlation in the Analysis of Cross-Classifications Having Ordered Categories. "Journal of American Statistical Association", 76:3, 2034.

[10] Tullock, G. (1967), "The Welfare Costs of Tariffs, Monopolies and Theft", Western Economic Journal, vol. 5, pp. 224-32.

[11] Fairbanks, Michael. (2005). Changing the Mind of a Nation: Elements in a Process for Creating Prosperity, "in Culture Matters", Huntington, editors, "New York: Basic Books", pp.270-281.

[12] Mueller, D.C. (2003), Public Choice III, Cambridge: Cambridge University Press.

[13] Olson, M. (1965), The Logic of Collective Action, Cambridge, MA: Harvard University Press.

[14] Hotlling, H. (1929), "Stability in Competition", Economic Journal, vol. 39 , pp. 41-57.

[15] Buchanan, J.M. (1980), "Rent Seeking and Profit Seeking", in J.M. Buchanan, R.D.

[16] Monroe, K.R. (1991), "The Theory of Rational Action: What is it? How Useful is it for Political Science", in W. Crotty (ed.)

[17] Bhagwati, J. (1982), "Directly Unproductive Profit Seeking Activities", Journal of Political Economy, vol. 90, pp. 988-1002.

[18] Diewert, W. Erwin, (1976). Exact and Superlative Index Numbers,' Journal of econometrics May 1976, 4: 115-45.

[19] Goodman, L.A., (1981a). Association models and the Bivariate Normal for Contingency Tables with Ordered Categories. Biometrica, $68: 347-55$.

[20] Eurostat /JP (2010): European Data Agency, "Eurostat-Online data code (t2020_20), OECD statistics at regional level".

[21] Haritou A., Nwaubani J C. (2008). "Categorical Data Analysis Working paper" (University Press).

[22] Haritou A., Nwaubani J C. (2010). "Categorical Data Analysis Working paper" (University Press).

[23] UN - Eurostat Population "European Commission, Department of Economic and Social Affairs.” 27 January 2017. 